the present situation of the dental profession in India. ${ }^{3}$

The Government should not entertain proposals to start new dental colleges without adequate dental manpower and infrastructure for the next ten years. Oral health policy needs to be implemented as a priority in India, with an emphasis on strengthening dental care services under public health facilities. ${ }^{4}$ It may be inferred that the current situation of the dental profession is because of poor implementation of government public health policies and not because of a lack of dental professionals in India. ${ }^{4}$

Thorakkal Shamim, Malappuram, India

1. Samuel SR. Dental education: Too many graduates in India. Br Dent J 2016; 220: 219.

2. Dental Council of India. Policy Decision: Staff $\&$ Infrastructural facility. Available at: http://www. dciindia.org.in/Admin/NewsArchives/policy_decission.pdf (accessed April 2016).

3. Shamim T. Continuing dental education (CDE) points: serious concerns. Indian J Med Ethics 2016; 13: 64

4. Shamim T. Oral health policy amicable for the South Asian Association for Regional Cooperation Nations. Iran J Public Health 2014; 43: 1589-1590.

DOI: 10.1038/sj.bdj.2016.281

\section{ORAL HEALTH PROMOTION}

\section{Oral health or social scourge}

Sir, in the paper on the economic benefits to the NHS on increased use of sugarfree gum in the $\mathrm{UK}^{1}$ savings are projected of between $£ 1.2$ and $£ 8$ million depending on what you want to believe. That of course is always assuming that the target population do not buy the sugared Juicy Fruit variety...

The authors are conveniently ignoring the social costs of cleaning up discarded gum. The clean-up costs nationally are estimated to be some $£ 60$ million as suggested by the Local Government Association. ${ }^{2}$ The LGA suggest that the average piece of gum costs about $3 p$ to buy - but 50 times that to clean up (£1.50). Most chewing gum never biodegrades and once it is trodden into the pavement requires specialised equipment to remove. Indeed they have asked, in vain, that gum manufacturers should also be switching to biodegradable and easier-to-remove chewing gum.

So the net overall cost to other parts of the public purse may be quite different. Six hundred and eighty-five thousand children aged 12 - say 20\% - chew gum twice a day. Let's say 274,000 increased chewing gum events and $20 \%$ of that gum is disposed of in a public place (they are 12-yearolds, after all). This suggests about 55,000 unwanted chewing gum disposal events, PER DAY, equating to an anticipated cleanup cost burden of $£ 30$ million.

A stated saving of up to £8 million translates into a net burden to the public purse of some $£ 22$ million.

And then I read the Conflict of Interest. 'Funded by a chewing gum manufacturer Oral Healthcare Programme.' Shame on the $B D J$. I am amazed Professor Kay would lend her name to such a blatant pseudo-ethical marketing ploy.

\section{Lister, Romsey}

1. Claxton L, Taylor M, Kay E. Oral health promotion: the economic benefits to the NHS on increased use of sugarfree gum in the UK. Br Dent J 2016; 220: 121-127.

2. Local Government Association. Chewing gum manufacturers urged by councils to pay for clear-up of gum-spattered streets. 22 November 2014. Available at: http://www.local.gov.uk/mediareleases/-/journal_content/56/10180/6745145/ NEWS (accessed 15 March 2016).

The authors Matthew Taylor, Lindsay Claxton and Liz Kay respond: Thank you for sharing your concerns.

The study sought to specifically assess whether sugarfree gum, based on its proven and recognised clinical benefits, ${ }^{1-7}$ may play a role in helping to reduce the economic burden of tooth decay to the NHS. For the purposes of the analysis and, as per most economic models, it is necessary to work from set assumptions and parameters in relation to the specific question being asked. Therefore, the potential impact of littering was not reviewed; however, neither was the important impact that improving oral health has on an individual's quality of life and well-being, such as avoiding pain and infection, missing school/college days and parents losing work days, nor the lifetime impact of having caries as a child.

We do, however, agree that littered gum is a concern that should not be ignored. Whilst the majority of people who chew gum do the right thing, a minority of people dispose of it irresponsibly and these consumers need to dispose of their litter properly. The gum manufacturing industry and campaign groups such as Keep Britain Tidy have dedicated significant resources to understanding the impact of littered gum and tackling it. They are agreed that the only long-term sustainable solution to this issue is through education and behaviour change to ensure the minority of chewers who continue to drop their gum do the right thing and put it in the bin. Over the last decade, significant resources have been dedicated to understanding the impact of littered gum and there has been considerable investment in programmes and initiatives focused on driving long-term sustainable behavioural change.

Although funded by gum manufacturers, the research was undertaken independently by the York Health Economic Consortium (part of the University of York) and Plymouth
University (in Liz Kay's capacity as a Professor of Dental Public Health). Prior to publication in the British Dental Journal, the research underwent rigorous independent peer review in order to ensure it met the required standards of scientific validity for publication.

Caries is one of the most common, largely preventable, problems in the UK, and we know that early decay has a life-long effect on health and wellbeing. With over a third (34\%) of 12-year-olds in the UK showing signs of obvious decay in their permanent teeth, ${ }^{8}$ we believe it is important that we examine all potential avenues for prevention and seek innovative new solutions to minimise the health and economic impact of caries.

1. Alcantara E, Leveille G, McMahon K, Zibell S. Benefits of chewing gum: oral health and beyond. Nutrition Today 2008; 43(2).

2. Leach SA, Lee G T, Edgar WM. Remineralization of artificial caries-like lesions in human enamel in situ by chewing sorbitol gum. J Dent Res 1989;68: 1064-1068.

3. Creanor S L, Strang R, Gilmour W H et al. The effect of chewing gum use on in situ enamel lesion remineralization. J Dent Res 1992; 71: 1895-1900.

4. Beiswanger B B, Boneta A E, Mau M S, Katz BP, Proskin HM, Stookey $G$ K. The effect of chewing sugar-free gum after meals on clinical caries incidence. J Am Dent Assoc 1998; 129: 1623-1626.

4. Szöke J, Bánóczy J, Proskin H M. Effect of after-meal sucrose-free gum-chewing on clinical caries. J Dent Res 2001; 80: 1725-1729.

5. Oral Health Foundation. Caring for teeth - sugarfree chewing gum. Available at: http://www.dentalhealth.org/tell-me-about/topic/caring-for-teeth/ sugar-free-chewing-gum.

6. FDI World Dental Federation. Oral health worldwide: A report by FDI World Dental Federation. Available at: http://www.worldoralhealthday.com/wp-content/uploads/2014/03/FDIWhitePaper_OralHealthWorldwide.pdf.

7. Health \& Social Care Information Centre. Child Dental Health Survey 2013, England, Wales and Northern Ireland [NS]. 19 March 2015. Available at: http://www.hscic.gov.uk/catalogue/PUB17137.

DOI: 10.1038/sj.bdj.2016.282

\section{SUGAR TAX}

\section{Caries is the disease}

Sir, the BDA should congratulate George Osborne on imposing a tax on sugary drinks in the recent budget in an attempt to reduce the incidence of a major disease in the UK. Unfortunately, he gave that disease the wrong name. It should have been dental caries rather than obesity! This is the one disease where evidence supports sugars having a contributory role.

Obesity, however, is not a disease, but a disorder with just one cause, calorie intake exceeding calorie expenditure.

Hopefully at the legislative stage, the tax will refer to 'non-milk extrinsic sugars' and not just 'sugar'. An error then might result in a tax on milk!

J. A. Beeley, Glasgow DOI: $10.1038 /$ sj.bdj.2016.283 